\title{
The Social Dimension of Participation and Completion in MOOCs
}

\author{
Valentina Goglio ${ }^{1,2 *}$ and Paolo Parigi ${ }^{2,3}$ \\ ${ }^{1}$ University of Turin, Italy // ${ }^{2}$ Stanford University, Stanford, CA, USA // ${ }^{3}$ Facebook, Menlo Park, CA, USA // \\ valentina.goglio@unito.it//pparigi@stanford.edu
}

${ }^{*}$ Corresponding author

(Submitted April 14, 2020; Revised June 14, 2020; Accepted October 3, 2020)

\begin{abstract}
The rapid and impressive development of Massive Open Online Courses (MOOCs) in less than half a decade has generated contrasting arguments about their social dimension. This paper investigates how the socio-economic background of learners affects their own experience and chances of course completion. The analyses test whether learners with a low socio-economic status (SES) have fewer chances of completing the online course and whether participation in online discussion forums moderates the role of SES. The data comes from two MOOCs provided by Stanford University. We find a negative association between low SES, course completion and course engagement. Moreover, we find that forum participation plays an ambiguous role, reinforcing the advantage of well-educated learners enrolled in one course, while it has no significant effect on the other course. The article concludes with some policy implications on social stratification in MOOCs and with some design suggestions for creators of MOOCs.
\end{abstract}

Keywords: MOOCs, SES, Social inequality, Higher education

\section{Introduction}

Between 2008 and 2012, the outburst of Massive Open Online Courses (MOOCs) in the USA created great excitement about their potential, putting them among the key challenges for the future of higher education. The hype that characterized the earlier period seems to be gone. MOOCs no longer enjoy the same attention in the media that they did in 2012-2013, however the number of users registered on the main MOOCs platforms is impressively high and keeps growing (Shah, 2019). This phenomenon has generated contrasting arguments (Sharrock, 2015). On one hand, these resources are enthusiastically welcomed as opening a series of opportunities for reducing social inequalities and promoting growth and employment. On the other, skeptics question the real empowering and equalizing effect of MOOCs.

Previous research has highlighted that MOOCs tend to attract already advantaged individuals. MOOC participants tend to be well-educated individuals, living in developed, mainly English-speaking countries (Emanuel, 2013). Highly educated learners are those with higher chances of completing the course, while learners from the Global South or countries with a medium to low Human Development Index (HDI), and women, tend to be disadvantaged in terms of persistence, completion and grades (Kizilcec \& Halawa, 2015). Even within developed countries like the USA, analysis of the geolocation of learners based on zip codes showed that, although diffusion is quite widespread, the largest concentration of learners comes from wealthy neighborhoods (Glass et al., 2016). Yet, less advantaged individuals may have higher returns from MOOC attendance and completion (Hout, 2012), associated with lower costs and access barriers compared to formal education. Key factors which -in principle- may incentivize their persistence and completion.

As highlighted by van de Oudeweetering and Agirdag (2018a) in their systematic review of the literature, there is no univocal evidence about the social implications of MOOCs for underprivileged learners. On one hand, the empirical studies considered show an advantage for highly educated and employed individuals. However, not all proxies for the socio-economic status of learners are taken into consideration (e.g.: occupation is often overlooked) and results in terms of completion and engagement provide mixed evidence, suggesting that MOOCs may serve particular underprivileged groups in unforeseen ways.

The article aims to make a contribution in this direction, testing the association between some socio-economic characteristics and outcomes in terms of course engagement and participation. We consider two possible outcomes for MOOC learners: (i) completion, the attainment of a certificate of accomplishment; and (ii) engagement, defined as having solved a certain number of problems (setting the threshold at $60 \%$ ). Moreover, the research design includes learner participation, operationalized as participation in an online forum by posting messages. The aim is to test whether the relationship between proxies for SES and outcome variables is moderated by participation in online forum discussions. 
The empirical analysis proposed is relevant for two reasons. First, the high and growing number of learners enrolled in MOOCs means that these courses became a "common event" for many different people. Such widespread coverage makes it a socially relevant fact that deserves further attention with regard to its social implications, not only to pedagogical aspects associated with the learning experience. Second, the pervasive rhetoric of equalization and democratization of access to education that accompanied the diffusion of MOOCs is now being reconsidered and this work helps shed light on whether the association between SES and educational achievement -demonstrated by social stratification research- holds true also in the particular domain of MOOCs.

\section{Theoretical framework}

\subsection{Inequality of educational opportunities}

A long tradition of studies has proven the link between social origin, access and attainment of higher education, and the key role played by cultural capital and economic resources of the family of origin in shaping the different chances of children attaining post-secondary education. Children of families with high socio-economic status (measured as economic resources, educational titled or cultural capital) show higher attainment levels, higher grades and higher chances of attaining post-secondary education. The seminal work by Blau and Duncan (1967) was the first to empirically address this relationship, demonstrating the extent to which family background influences college attainment. Educational transition model literature (Mare, 1981) showed that the advantage of high socio-economic origin and its social-psychological benefits becomes particularly important for the highest transitions (i.e., college). Subsequent works further revealed how the socio-economic background of the family is one of the strongest predictors of college completion (though not the only one) (Roksa et al., 2007; Rosenbaum et al., 2009). Several studies investigated such association in a comparative perspective: the seminal work by Shavit and Blossfeld (1993) confirmed the stability of the effect of social origin on educational transitions, with their findings being subsequently contested by further analysis showing equalization trends in European countries.

The process of educational expansion that occurred in the second half of the $20^{\text {th }}$ century seems to have contributed to reducing the relative inequality in access and attainment of higher education in the USA and in Europe (Bernardi \& Ballarino, 2014; Breen, 2010; Breen \& Jonsson, 2005). However, this process is only partial and a better examination of different measures of inequality and an encompassing analysis of dynamics throughout the whole $20^{\text {th }}$ century reveals a more complex picture. Indeed, the process of expansion of access that characterized the higher education system in the USA after World War II, accompanied by public policy intervention, expanded enrollments. Yet, it was also accompanied by an increasing stratification of the system, with expansion occurring mainly at low-status institutions while the advantage associated to higher social status did not decrease (Roksa et al., 2007). A recent analysis of the dynamics of educational inequality in the USA envisages a possible increase in inequality of educational attainment for younger people, born after 1990, who experience the combination of decreasing financial support for education and increasing wage inequalities (Bernardi, Hertel, \& Yastrebov, 2018).

Comparative analysis shows that this trend is accompanied by processes of horizontal stratification (Shavit et al., 2007): according to the "effectively maintained inequality" approach (Lucas 2001), parental education still plays a critical role in terms of quality, reputation and duration of the course attended, even in terms of prestige of the field of study. In a context of expansion of access to education, more affluent families mobilize their resources to secure educational credentials that are qualitatively superior and more prestigious in order to guarantee better outcomes to their offspring (Gerber \& Cheung, 2008). Empirical research on European countries confirms that individuals with culturally advantaged parents are more likely to attain more rewarding, longer and prestigious educational qualifications from high quality institutions (Triventi, 2013; Triventi et al., 2017). We have summarized this literature with the following hypothesis:

H1: We expect to find a negative association between low SES and completion of the MOOC, represented by the attainment of a certificate of accomplishment (outcome 1)

\subsection{Completion and participation in MOOCs}

The definition of success in particular types of online courses like MOOCs is still subject to discussion by academics and the general public (Ho et al., 2015). The main objection to the attainment of a certificate of completion in MOOCs as a measure of success is that it may not have the same informative value that it has in 
the domain of traditional education (Evans \& Baker, 2016a; Evans et al., 2016b; Kizilcec et al., 2013). Yet, consensus over alternative definitions and measurement of success in MOOCs has not been reached yet. Evans and Baker (2016a) compare different indicators of persistence besides the attainment of a certificate of completion and propose more inclusive measures of "success" in MOOCs, such as the cumulative grade reached by the learner or the percentage of videos watched, and an associated threshold for achievement. They identify three different outcome variables of interest: (i) engagement; (ii) persistence; (iii) completion, and analyze the factors at student, lecture and course-level affecting the results. Kizilcec, Piech, and Schneider (2013) draw a typology of MOOC learners and identify four types, pointing to the different uses that learners make of MOOCs, and to a more complex understanding of the multifaceted group of those who do not complete all activities.

Despite contrasting views, the certificate of completion and the number of activities completed during the course is still considered a valuable piece of information about learners' behavior and success (Almeda et al., 2018; Reich, 2014; Wang \& Baker, 2018).

H2: we expect to find a negative association between low SES and engagement in the MOOC, defined as having taken at least $60 \%$ of the quizzes available (outcome 2)

Most MOOCs also include an online discussion forum where learners can interact through forum posts, starting discussions on the class's topic autonomously, replying to discussions or assignments launched by the teacher or seeking advice on course material among peers or from the teacher. This feature represents an attempt to address student and teacher frustration due to the lack of social interaction typical of the physical classroom (Beard et al., 2004). Participation in online forum discussions can represent a substitute for classroom interaction and, despite their limitations and distinctive features, it can be argued that they tend to reproduce some of the social stratification mechanisms typical of face-to-face interaction in formal schooling.

Empirical literature on the type of participation in MOOC online forums and the social characteristics of people engaged in this activity is still limited. Most of the research available points to a positive association between participation in forum discussions and positive outcomes in MOOCs (Almeda et al., 2018; Zhang et al., 2017). However, the empirical findings on the social and demographic characteristics of learners posting on the MOOC forum are limited and often contradictory (Ruthotto et al., 2020). Research into traditional classroom interaction showed that participation is positively correlated to learning outcomes (Rocca, 2010) but is not evenly distributed across social groups and can be challenging for certain categories of learners, such as students from lower SES or minority groups (Chang, 2005). In this respect, the Bourdieu concept of cultural capital can prove helpful: interacting with other students or the teacher requires cognitive skills, competence, social abilities and specific attitudes toward education. These represent primary effects of the class of origin, an incorporated form of cultural capital transmitted from high social status families to their offspring (Sallaz \& Zavisca, 2007; Schizzerotto \& Barone, 2012). This ultimately turns into a cycle that reinforces inequality for highly educated individuals who already possess good skills for succeeding in learning, but are also further advantaged by their ability to interact and benefit from this interaction with others in the online discussion forum, resulting in better learning outcomes.

Empirical research into interaction through digital media also highlights the fact that anonymity, missing social clues and lower emotional involvement in computer-mediated communication may contribute to the creation of a neutral and more inclusive environment, fostering participation by all (Gunn et al., 2003; Kollock \& Smith, 1996). This suggests a technicist hypothesis in which the particular context of the online discussion forum of MOOCs may activate traditionally less active students. The anonymity granted by missing social clues in the online discussion forum may act as a digital filter, reducing the stress associated with exposing personal thoughts to the judgment of others. In the case of MOOCs, participation in online discussion forums may positively moderate the relationship between socio-economic characteristics of the learner and course completion and engagement:

H3: we expect to observe that participation in online forums positively moderates the negative effect of low SES on both completion and engagement. We expect to find that low SES learners who write at least one forum post have better chances of completing or staying engaged than their peers who do not participate in the forum

\section{Material and methods}

The empirical analyses presented in the paper use secondary data from two different MOOCs provided by Stanford University through their OpenEdX instance, Lagunita. The data include demographic, performance and 
survey-related information on learners registered in two MOOCs: "Statistical Learning" (hereafter SL) and "America's Poverty and Inequality" (hereafter API), released in 2016, respectively in the Winter and Fall term.

The SL course is an introductory-level course in statistical modeling and data science, with a focus on regression and classification methods, developed by professors T. Hastie and R. Tibshirani. It consists of 9 modules (selfpaced) and the workload is estimated at 3-5 hours per week.

The API course is developed by the Stanford Center on Poverty and Inequality and deals with income inequality, poverty, racial and gender inequalities in the USA. It is an introductory level course consisting of 9 modules (self-paced) and requires about 2 to 4 hours of study per week.

The two courses are not a representative sample of online classes but were chosen following the strategy of maximizing differences across courses available in Lagunita and assuring a sufficient sample size.

The demographic information and survey data come from an embedded pre-course survey, designed by the CAROL research team at Stanford University, administered to learners at the very beginning of the MOOC (after enrollment, before module 1). We are aware of issues associated with response errors in the MOOC surveys, leading to inaccurate representations of the population of learners and bias in estimating the effect of demographic variables. However, as indicated by van de Oudeweetering and Agirdag (2018b), embedded web surveys help increase the response rate (compared to email surveys) and help reach learners who are generally less-responsive, ultimately reducing response bias. Table 1 below supports this argument: among people who completed the course, the survey response rate of the is just below 50\%, providing a solid source of data to describe dynamics among completers. Dropouts, i.e., those that did not complete the course and did not answer the survey, are outside the scope of this paper.

Table 1. Learners who completed the courses and survey respondents

\begin{tabular}{lccc}
\hline Responded to & \multicolumn{3}{c}{ Completed course } \\
pre-course survey & Yes & No & Total \\
\hline Yes & $48 \%$ & $13 \%$ & 10,787 \\
No & $52 \%$ & $87 \%$ & 62,067 \\
\hline Total & $100 \%$ & $100 \%$ & 72,854 \\
& $(N=4,491)$ & $(N=68,363)$ & \\
\hline
\end{tabular}

The empirical strategy uses quantitative methods of analysis based on logistic regression analysis to investigate the direct and indirect relationship between the socio-economic background of learners and MOOC completion and engagement. Models are run separately for the two courses, due to the different sample size and definition of the dependent and independent variables.

\subsection{Dependent variables}

In order to take into consideration different approaches to "success" in MOOCs, we considered two outcome variables. The first is "completion," defined as a dummy variable equal to 1 if the learner downloaded the certificate of accomplishment available at the end of the course. This may not be the perfect variable for completion, as not all learners may be interested in downloading the certificate at the end of the course. Yet, such information is available for both courses and is freely downloadable. Rules of attainment change slightly between the courses: learners must have earned at least $50 \%$ of graded assignments for SL, with at least $75 \%$ for the API course. This difference can lead to a more restricted sample of completers for the second course.

The second outcome variable is the percentage of quizzes answered, a proxy for engagement. The courses analyzed are organized in several chapters. Each includes a video lecture and an assessment in the form of a multiple-choice quiz (the proportion of video lectures watched was also considered but the two activities are highly correlated, about 0.75 ). The minimum level of engagement is coded as at least $60 \%$ of quizzes answered, irrespective of the score attained, out of the total number of quizzes available.

\subsection{Independent variables}

Typically, literature on social stratification refers to the level of education and occupational category of parents, as well as family and personal income or job prestige as proxies for SES (Breen \& Jonnson, 2005; Ganzeboom et al., 1992; Shavit \& Blossfeld, 1993). The data available for this study offer limited information on these 
indicators. Consequently, the study relies on a series of other variables that are only implicit indicators of the socio-economic background: (i) educational attainment of the learner; (ii) self-declared employment status; (iii) educational attainment of parents (for the API course only). Employment status can be considered an imperfect but pragmatic indicator of current socio-economic status of the individual when information on the type or prestige of the job is not available. Indeed, jobless individuals are a vulnerable group exposed to greater risk of poverty and social exclusion due to lack of economic resources from paid employment, but also to reduced or poor quality professional and social networks compared to employed learners (Gallie \& Paugam, 1999). In addition, with regard to educational attainment, when the sample is made up of adult individuals the influence of parental background is still present but more distant (Kizilcec \& Saltarelli 2019), making current individual status more relevant.

The moderating factor in the model - participation in the online discussion forum of the course - is defined as equal to 1 if the learner wrote at least one forum post after the second video watched; equal to 0 if the learner (i) did not write any post or (ii) wrote a post before watching the second video. In order to mitigate the risk of endogeneity, where participation is correlated with motivation, influencing the outcome variable, forum posts written before watching the second video of the course are excluded (alternative arrangements were also considered, but the relationship among variables did not change. This decision is based on the assumption that writing before the start of the course or at the very beginning (e.g., before the second video) may indicate extremely high levels of motivation of the learner (ultimately influencing the final outcome) and not actual requests for clarification or support on the study material. Finally, multicollinearity issues are excluded as VIF $=$ 1.60 for SL and VIF $=2$ for API.

\section{Results and discussion}

Table 2 provides a summary of the characteristics of learners in the two courses. The sample size of demographic and survey data varies widely between the two courses, with SL attracting a much higher number of learners than API (25 times more). The latter shows better engagement proxies with a higher proportion of: (i) respondents to the pre-course survey, (ii) certificates attained (despite the more restrictive rule for the Certificate of Accomplishment) and (iii) written online forum posts. Women are underrepresented in SL, while the distribution of educational qualifications is quite similar in both courses and oriented toward high levels of education, with a high proportion of learners with Master's Degrees. Employed and unemployed people are equally represented in both courses, while SL has a higher proportion of students; API has a higher proportion of retired people and a residual category of people not falling within any of the other standard employment categories (other).

Table 2. Sample characteristics

\begin{tabular}{|c|c|c|c|c|}
\hline & \multicolumn{2}{|c|}{ Statistical learning } & \multicolumn{2}{|c|}{ Poverty and inequality } \\
\hline & $N$ & $\%$ & $N$ & $\%$ \\
\hline Total N & 72,854 & $100.00 \%$ & 2,908 & $100.00 \%$ \\
\hline \multicolumn{5}{|c|}{ Dependent variables } \\
\hline Took certificate of completion & 4,491 & $6.16 \%$ & 358 & $12.31 \%$ \\
\hline Answered at least $60 \%$ of quizzes & 4,256 & $5.84 \%$ & 469 & $16.13 \%$ \\
\hline \multicolumn{5}{|c|}{ Independent variables } \\
\hline Wrote at least one forum post & 989 & $1.36 \%$ & 397 & $13.65 \%$ \\
\hline Wrote post \& took certificate & 499 & $0.68 \%$ & 209 & $7.18 \%$ \\
\hline \multicolumn{5}{|c|}{ Demographic data } \\
\hline Female & 13,937 & $22.22 \%$ & 1,609 & $55.33 \%$ \\
\hline \multicolumn{5}{|l|}{ Educational attainment } \\
\hline Less than BA & 6,035 & $8.28 \%$ & 298 & $10.25 \%$ \\
\hline Bachelor's & 23,481 & $32.23 \%$ & 763 & $26.24 \%$ \\
\hline Doctorate & 7,155 & $9.82 \%$ & 373 & $12.83 \%$ \\
\hline Master's/prof. Degree & 25,781 & $35.39 \%$ & 1,173 & $40.34 \%$ \\
\hline Withheld & 9,180 & $12.60 \%$ & 292 & $10.04 \%$ \\
\hline \multicolumn{5}{|l|}{ Geographical distribution } \\
\hline USA & 24,988 & $34.30 \%$ & 2,072 & $71.25 \%$ \\
\hline Europe & 12,955 & $17.78 \%$ & 206 & $7.08 \%$ \\
\hline India & 9,001 & $12.35 \%$ & 39 & $1.34 \%$ \\
\hline China & 2,412 & $3.31 \%$ & 21 & $0.72 \%$ \\
\hline \multicolumn{5}{|c|}{ Survey data } \\
\hline
\end{tabular}




\begin{tabular}{lcccc}
\hline Total N & 10,787 & $100.00 \%$ & 938 & $100.00 \%$ \\
Employment status & & & & \\
FT employed & 6,619 & $64.52 \%$ & 633 & $69.48 \%$ \\
PT employed & 662 & $6.45 \%$ & n.a. & n.a. \\
Student & 2,106 & $20.53 \%$ & 85 & $9.33 \%$ \\
Unemployed & 766 & $7.47 \%$ & 50 & $5.49 \%$ \\
Retired & 106 & $1.03 \%$ & 88 & $9.66 \%$ \\
Other & n.a. & n.a. & 55 & $6.04 \%$ \\
Parental education & & & & \\
High school or less & n.a. & n.a. & 270 & $29.54 \%$ \\
Associate/Some College & n.a. & n.a. & 273 & $29.87 \%$ \\
Bachelor's & n.a. & n.a. & 54 & $5.91 \%$ \\
Master's/PhD & n.a. & n.a. & 317 & $34.68 \%$ \\
& Other independent variables & & \\
No. Posts written & Mean & SD & Mean & SD \\
Age & 3.18 & 6.39 & 6.21 & 13.23 \\
\hline
\end{tabular}

Note. Source: Own elaboration on Stanford Lagunita data.

\subsection{Certificate of completion}

Starting from the course in SL, Model 1 in Appendix A shows the odds ratio of the logistic regression model with outcome variable the attainment of a certificate of completion and proxies for SES as predictors. An odds ratio greater than 1 indicates a positive association, while an odds ratio lower than 1 indicates a negative association. Figure 1 shows the average marginal effects of SES proxies, indicating actual differences in the probability of attaining a certificate of completion for each group considered (Leeper, 2018). The left panel indicates the estimated average marginal effect for the level of education of learners (reference category: less than bachelor's degree); the right panel represents estimates for the employment situation of the learner (reference category: full time employment). Results for the former support the hypothesis of a relative disadvantage of learners with low educational qualifications: indeed, learners with a university education, in particular $\mathrm{PhD}(+9$ p.p.) and, to a lesser extent, master's graduates $(+3.6$ p.p.) have a higher chance of completing the course, compared to their peers without a college degree.

As far as the employment situation is considered, the middle panel shows that unemployed individuals have a 5 p.p. higher chance of attaining a certificate of accomplishment compared to individuals who are in full time employment. This may suggest that unemployed learners may be more motivated towards gaining and updating skills and may view or use the certificate of completion as a signaling tool for increasing their employment prospects. Their potentially disadvantaged condition (see van de Oudeweetering \& Agirdag, 2018a) seems to works as an incentive for an "instrumental" use of the course, referring to Max Weber's theory of social action (Weber, [1922] 1978). By completing the course and attaining a certificate, unemployed learners pursue a "goal rational" type of social action, aimed at acquiring new skills or updating existing ones and, at the same time, showing prospective employers their skills and willingness to continue learning (Castaño-Muñoz et al., 2017).

The model then tests whether participation in the online forum has a moderating role on the relationship between SES proxies and completion, indicating whether or not writing at least one forum post is associated with an advantage for certain groups (in the chances of completion with a certificate).

Table 3 shows the odds ratio of the regression model including the interaction effect between writing at least one forum post (after watching the second video) and each predictor. Writing at least one forum post has a positive and strong direct association with the chances of attaining a certificate of completion. However, when introducing the interaction between level of education and having written at least one post (Model 1), the estimates show that there is no significant interaction between level of education and the writing of at least one forum post, with the only exception being those with a $\mathrm{PhD}(90 \%$ confidence interval), who have an advantage. This advantage remains when considering the main effect of the predictors, indicating that, among those who wrote at least one forum post, those with a $\mathrm{PhD}$ are the group that benefits the most. Model 2, on the other hand, shows a negative interaction of writing a forum post with the condition of being a student. However, when considering the main effect of the two interacting predictors, students who wrote a post still have an advantage, compared to their peers who did not write any forum post. 


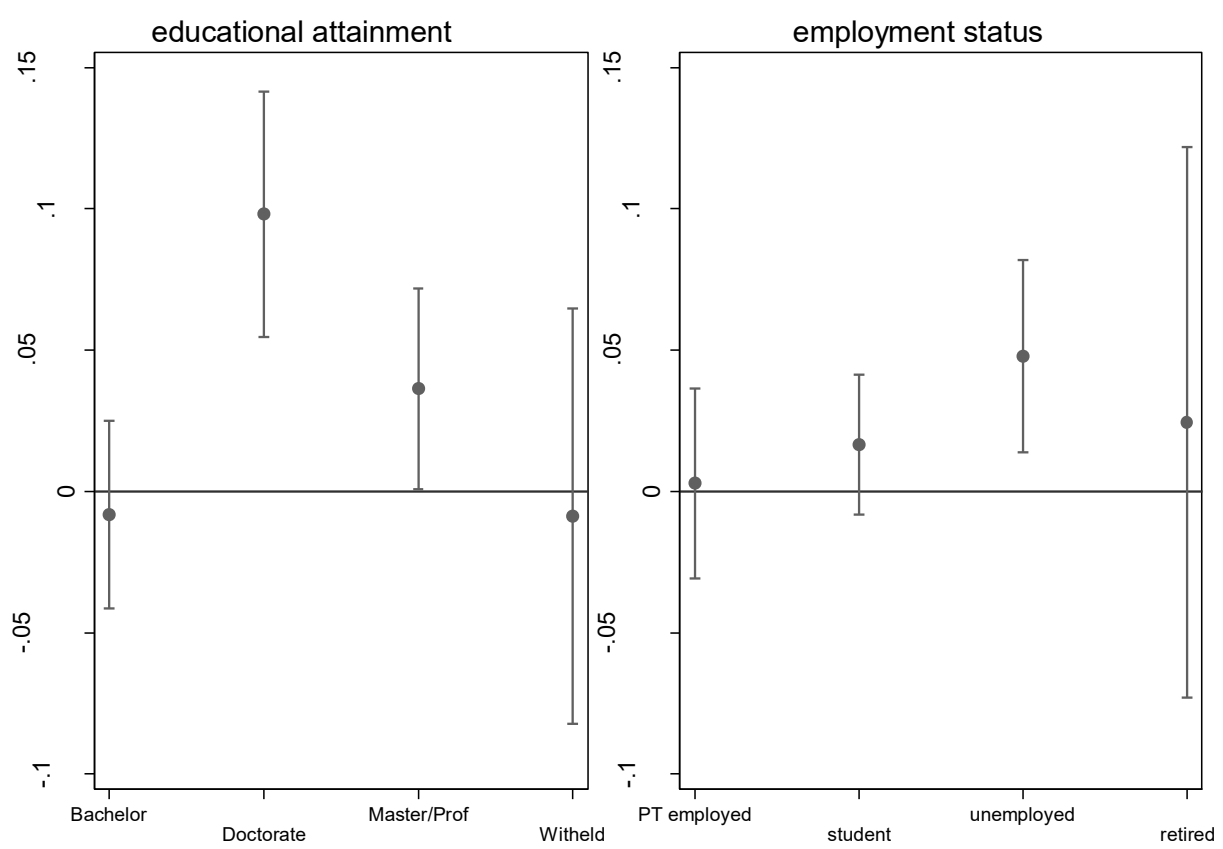

Figure 1. Statistical learning, average marginal effects for outcome $=$ completion

Table 3. Statistical learning. Estimates for logistic regression models with interactions (odds ratios) Model 1

Model 2

\begin{tabular}{lcc} 
& Model 1 & Model 2 \\
\cline { 2 - 3 } & Outcome $=$ certificate & Outcome = certificate \\
\hline Employment status (ref = FT employed) & & \\
PT employed & 0.954 & 0.997 \\
& $(0.107)$ & $(0.115)$ \\
Student & 1.108 & 1.147 \\
& $(0.0864)$ & $(0.0904)$ \\
Unemployed & 1.178 & 1.214 \\
& $(0.119)$ & $(0.127)$ \\
Retired & 0.938 & 1.043 \\
& $(0.300)$ & $(0.345)$ \\
Education (ref = less than BA) & & 1.020 \\
Bachelor's & 0.992 & $(0.122)$ \\
& $(0.121)$ & $1.894^{* *}$ \\
Doctorate & $1.806^{* *}$ & $(0.264)$ \\
& $(0.257)$ & $1.344^{*}$ \\
Master's/professional degree & $1.309^{*}$ & $(0.167)$ \\
Withheld & $(0.166)$ & 1.097 \\
Wrote at least one forum post (after the second video) & 1.112 & $(0.290)$ \\
& $(0.294)$ & $13.28^{* *}$ \\
Interaction education \&post & $5.353^{* *}$ & $(2.451)$ \\
Bachelor's \& post & $(2.285)$ & \\
Doctorate \& post & & \\
Master's \& post & 1.796 & \\
Withheld \& post & $(0.886)$ & \\
Interaction employment \&post & 2.738 & \\
PT employed \& post & $(1.524)$ & 0.495 \\
Student \& post & 1.733 & $0.220)$ \\
Unemployed \& post & $(0.810)$ & $0.1375^{* *}$ \\
\hline
\end{tabular}




\begin{tabular}{|c|c|c|}
\hline \multirow{2}{*}{ Retired \& post } & & $(0.221)$ \\
\hline & & $\begin{array}{c}0.437 \\
(0.335)\end{array}$ \\
\hline ex & $\mathrm{Y}$ & $\mathrm{Y}$ \\
\hline Age & $Y$ & $\mathrm{Y}$ \\
\hline Constant & $0.183^{* *}$ & $0.176^{* *}$ \\
\hline & $(0.0248)$ & $(0.0236)$ \\
\hline bservations & 9,111 & 9,112 \\
\hline
\end{tabular}

Note. Standard errors in parentheses; ${ }^{*} p<.05 ;{ }^{* *} p<.01 ;{ }^{* * *} p<.001$.

With respect to the second course analyzed, API, Figure 2 (and model 1 in Appendix B) shows the association between the selected proxies for socio-economic background of the learner and the chances of attaining a certificate of completion (awarded after $75 \%$ of correct answers in this course). Overall, the estimates seem to support our hypothesis of a positive association between higher SES and the chance of completion with a certificate, with some peculiar features. Indeed, contrary to that found for the other course, in this case there are no significant differences based on the educational level of the learner (left panel of Figure 2). When it comes to the employment status of the learner, unlike that observed for the other course, people involuntarily excluded from the labor market do not have a different chance of completing the course, compared to their employed peers. It is a residual category, individuals self-defined as having "other" employment status (not employed, nor unemployed or students), that shows a higher chance ( +22 p.p.) of completing the course with a certificate. Finally, the educational background of parents (available for this course only) does not show a robust association with the outcome variable, with the exception of a slightly significant advantage $(90 \%$ confidence interval) of learners with at least one parent with a university education ( +7 p.p. higher chance of completion with a certificate for offspring of parents with a Master's degree or $\mathrm{PhD})$.

The findings related to the residual category of "other" labor market status are unexpected and may indicate a particular group of completely inactive individuals. On one hand, they may fall within the definition of NEETs (not in education, employment or training). However, upon closer examination, individuals in this group tend to be adult learners (mean age $=43.9$, median age $=46$ ) and two-thirds are female learners $(67 \%$ ). This background could indicate that those learners may potentially come from better socio-economic backgrounds, as they can afford to stay out of the labor market (are not employed) without seeking employment (they are not unemployed), nor being in formal education (they are not students). In addition, taking into consideration the fact that (i) the definition of NEETs in Europe includes young people up to the age of 34 (Eurostat, 2019), while the sample here has a much higher average age; (ii) that $71 \%$ of the learners of this course come from the USA; (iii) that, in the USA, figures available for NEETs are significantly lower than in some European countries (OECD, 2018), we can argue that this category could represent an advantaged segment of MOOC learners.

Continuing with the reference to Max Weber's theory of action, in this case it can be argued that learners on the API course may follow a "value rational" type of social action, based on shared values on an important social issue. The instrumental value attributed to the SL course seems to fail in favor of a more value-oriented approach or recreational function of the course.

Table 4 shows estimates of the interaction between the predictors and participation in an online forum discussion. Model 1 confirms that employment status, and in particular being in the category of "other" is the strongest predictor and the fact that having written a post does not show any positive association either when considered alone or interacting with educational level. Model 2 shows no significant interaction between forum participation and different labor market situations, indicating that writing a forum post does not lead to any different outcome depending on the labor market situation. Model 3 shows that writing a forum post is positively associated with a higher chance of completion with a certificate and a slightly significant advantage of learners coming from highly educated parents who write a post. Among those who write at least one forum post after the second video, learners from highly educated parents have a higher chance of obtaining a certificate of completion compared to learners who participate but are from low educated parents, with a $90 \%$ confidence interval. 


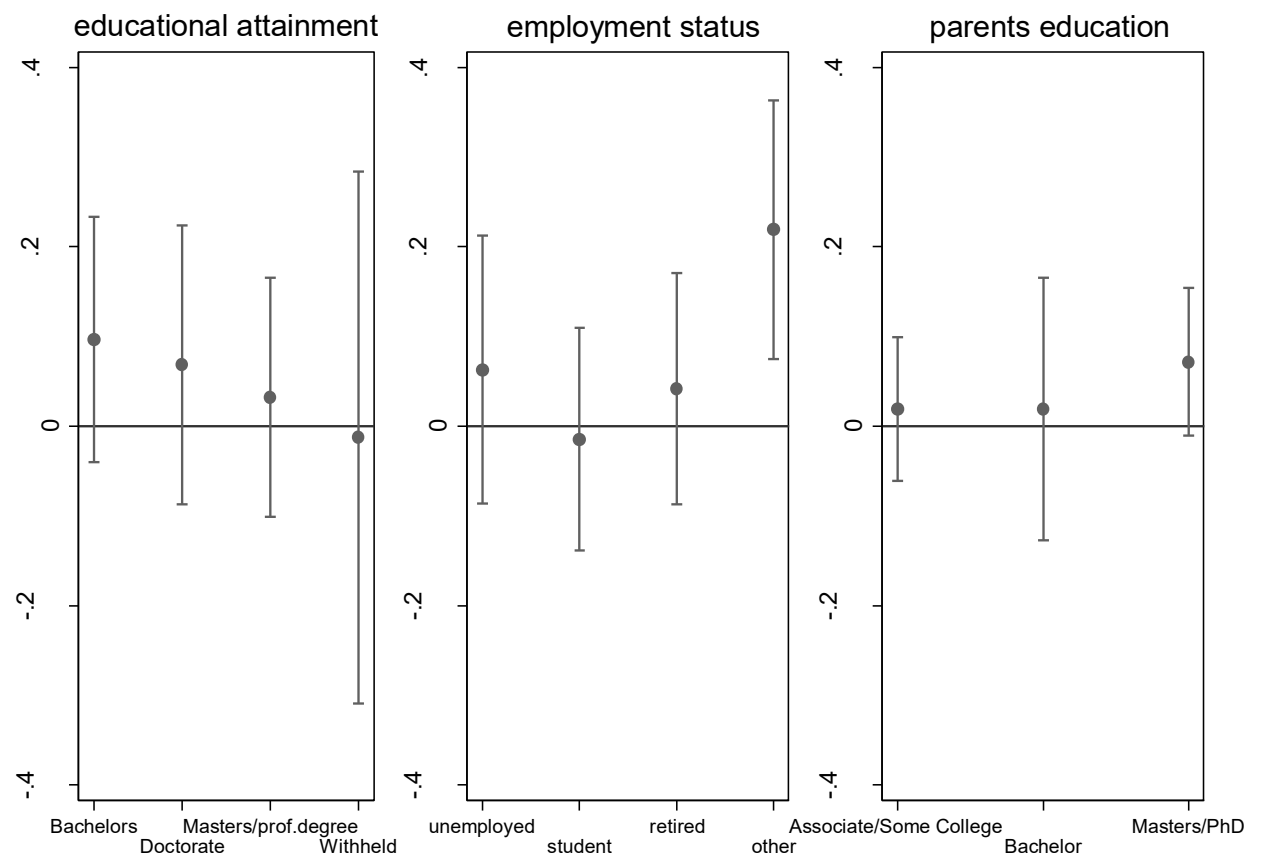

Figure 2. America's poverty and inequality, average marginal effects for outcome $=$ completion

Table 4. America's poverty \& inequality. Estimates for logistic regression model with interaction (odds ratio)

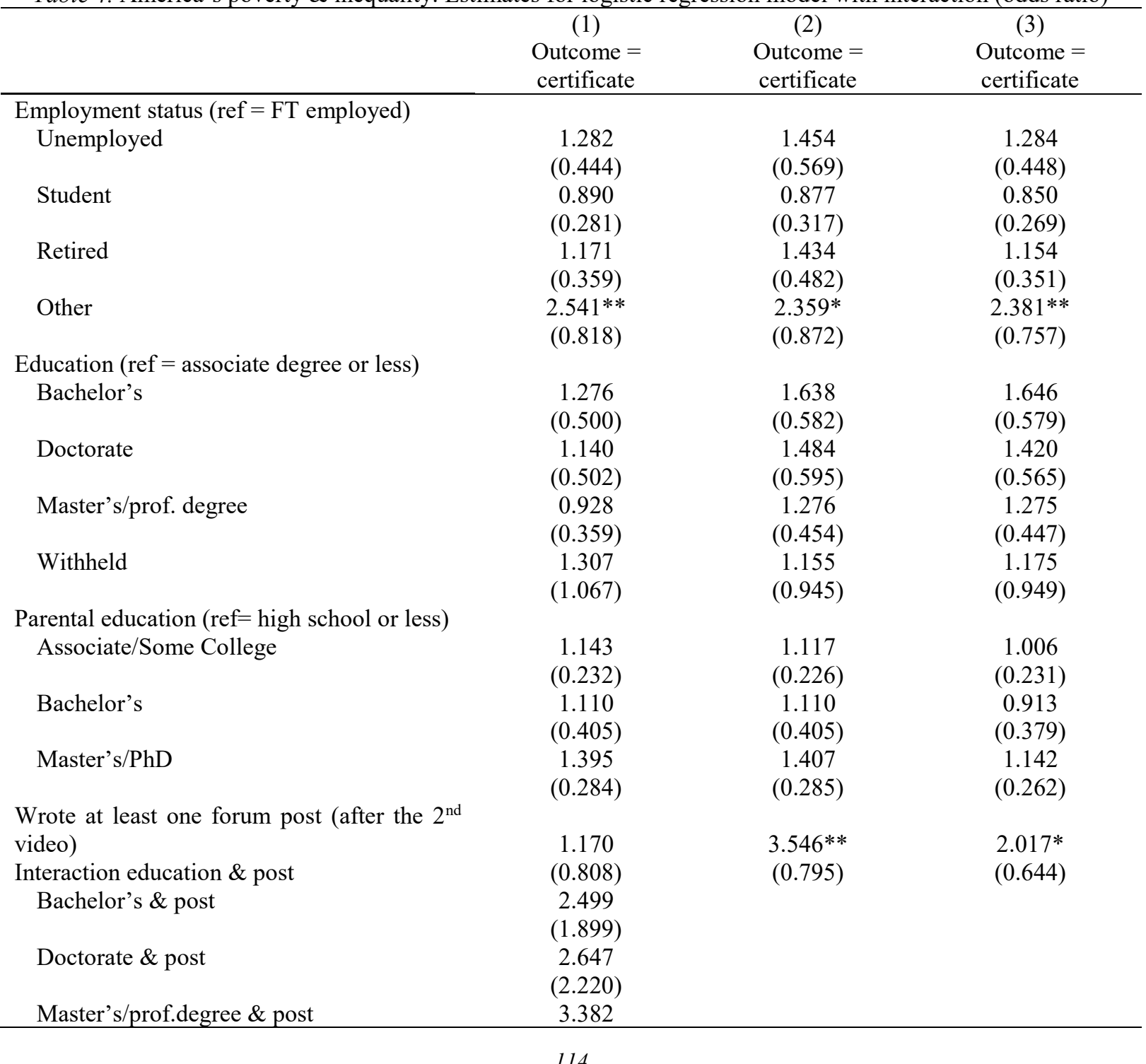




\section{$(2.515)$}

Interaction employment \& post

Unemployed \& post

Student \& post

Retired \& post

Other \& post

Interaction parental edu \& post

Associate/Some College \& post

Bachelor's \& post

Master's/PhD \& post

Sex

Age

Constant

Observations
$\mathrm{Y}$

$\mathrm{Y}$

$0.347 *$

$(0.146)$

\subsection{Engagement}

With respect to the first course analyzed, SL, Figure 3 shows the average marginal effect associated with two proxies for socio-economic background on the chances of responding to at least $60 \%$ of quizzes (regardless of the grade received) (for coefficients see model 2 in Appendix A). The left panel shows that the level of education is the only predictor showing a close and significant association: learners with a $\mathrm{PhD}$ or master's degree have a higher chance $(+11$ p.p. and +5 p.p.) of staying engaged throughout the course compared to their peers with less than a bachelor's degree, and values are similar to the case of course completion. The right panel on the other hand, shows that unemployed learners and students have a similar (limited) higher likelihood of staying engaged (+4 p.p. and +3 p.p.), although statistically significant at a $90 \%$ confidence interval only. Consequently, the advantage of unemployed learners observed for the attainment of a certificate of completion is no longer robust when considering the likelihood of taking at least $60 \%$ of the quizzes.

As far as the interaction with participation in forum discussions is considered, Table 5 shows the odds ratio of the interaction between participation in forum discussions and SES proxies. Neither model shows any significant interaction, indicating that writing a post is associated with a higher chance of engagement (main effect), but there are no significant differences across groups of learners (interactions), suggesting that participation in forum discussions does not play a moderating role between socio-economic status and engagement throughout the course.

Results for the API course are shown in Figure 4 (see model 2 in Appendix B for coefficients). The estimates for the likelihood of remaining engaged in the course reveal a slightly different situation compared to the attainment of a certificate.

As already observed, different educational levels (of the learner) are not associated with a higher or lower likelihood of staying engaged beyond $60 \%$ of course quizzes (left panel Figure 4). When looking at the employment status, the relative advantage of the residual category of the "other" labor market situation is confirmed (+16 p.p.), but this time together with a relative advantage of unemployed learners. Unlike the case of course completion, in the case of engagement, unemployed learners show a significantly higher likelihood of staying engaged throughout the course compared to employed individuals (+20 p.p.). Finally, social origin proxied by parental education- is not robust and significantly associated with different likelihoods of engagement in the course material, with the exception of a small and slightly significant advantage for children of highly educated parents. 


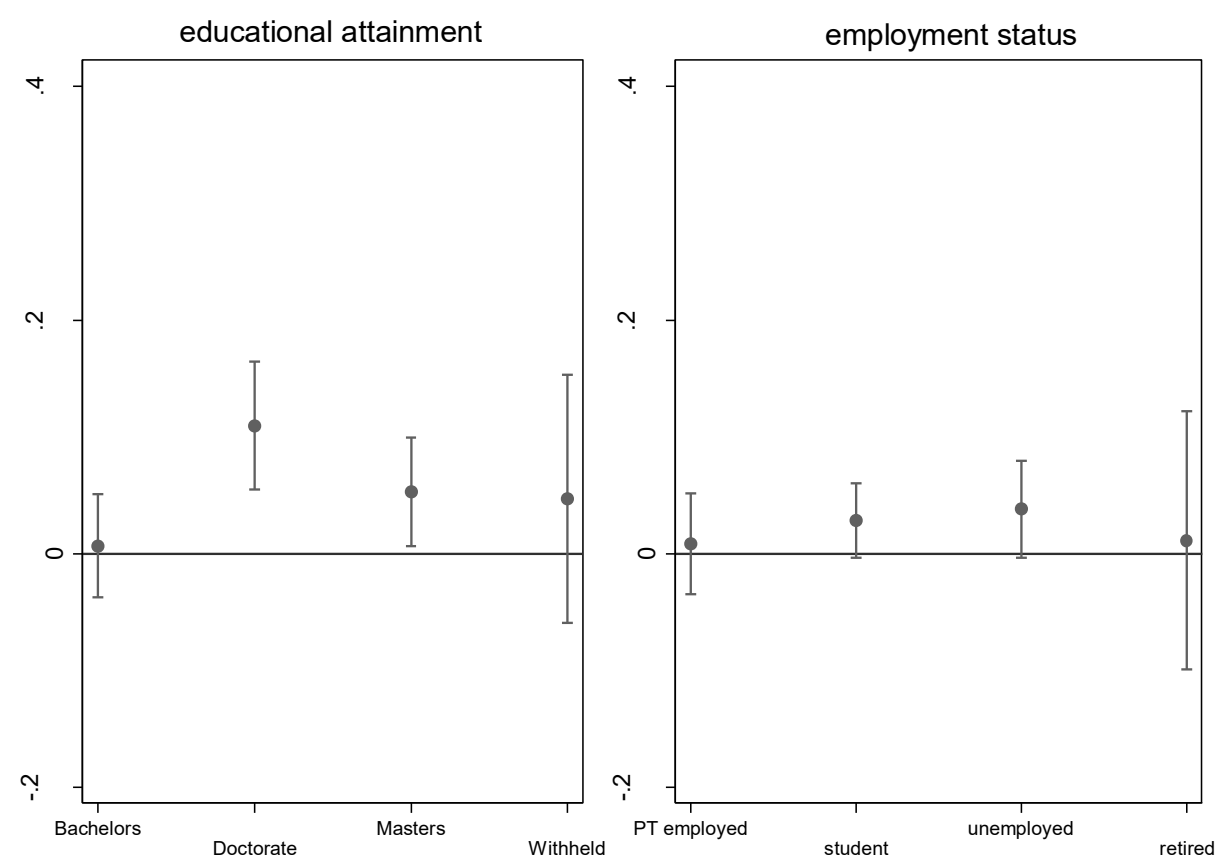

Figure 3. Statistical learning, average marginal effects for outcome = engagement

Table 5. Statistical learning. Estimates for logistic regression models with interactions (odds ratios)

\begin{tabular}{|c|c|c|}
\hline & Model 1 & Model 2 \\
\hline & Outcome=engagement & Outcome=engagement \\
\hline \multicolumn{3}{|l|}{ Employment status (ref = FT employed) } \\
\hline PT employed & $\begin{array}{c}1.015 \\
(0.113)\end{array}$ & $\begin{array}{c}1.052 \\
(0.120)\end{array}$ \\
\hline Student & $\begin{array}{c}1.147 \\
(0.0898)\end{array}$ & $\begin{array}{c}1.147 \\
(0.0908)\end{array}$ \\
\hline Unemployed & $\begin{array}{c}1.068 \\
(0.110)\end{array}$ & $\begin{array}{c}1.104 \\
(0.117)\end{array}$ \\
\hline Retired & $\begin{array}{c}0.921 \\
(0.270)\end{array}$ & $\begin{array}{c}0.961 \\
(0.294)\end{array}$ \\
\hline \multicolumn{3}{|l|}{ Education (ref $=$ associate degree or less) } \\
\hline Bachelor's & $\begin{array}{c}1.056 \\
(0.133)\end{array}$ & $\begin{array}{c}1.074 \\
(0.132)\end{array}$ \\
\hline Doctorate & $\begin{array}{l}1.854 * * \\
(0.269)\end{array}$ & $\begin{array}{l}1.862 * * \\
(0.265)\end{array}$ \\
\hline Master's/prof. Degree & $\begin{array}{l}1.377 * \\
(0.179)\end{array}$ & $\begin{array}{l}1.386^{*} \\
(0.177)\end{array}$ \\
\hline Withheld & $\begin{array}{c}1.540 \\
(0.411)\end{array}$ & $\begin{array}{l}1.566+ \\
(0.414)\end{array}$ \\
\hline Wrote at least one forum post (after the second video) & $\begin{array}{l}6.473 * * \\
(2.897)\end{array}$ & $\begin{array}{c}8.307 * * \\
(1.544)\end{array}$ \\
\hline \multicolumn{3}{|l|}{ Interaction education $\&$ forum post } \\
\hline Bachelor's \& post & $\begin{array}{c}1.384 \\
(0.720)\end{array}$ & \\
\hline Doctorate \& post & $\begin{array}{c}0.961 \\
(0.531)\end{array}$ & \\
\hline Master's/prof.degree \& post & $\begin{array}{c}1.038 \\
(0.508)\end{array}$ & \\
\hline Withheld \& post & Omitted & \\
\hline \multicolumn{3}{|l|}{ Interaction employment \& post } \\
\hline PT employed \& post & & $\begin{array}{c}0.532 \\
(0.240)\end{array}$ \\
\hline Student \& post & & 1.058 \\
\hline
\end{tabular}




\begin{tabular}{lcc}
\hline Unemployed \& post & & $(0.436)$ \\
& & 0.633 \\
Retired \& post & & $(0.241)$ \\
& & 0.604 \\
Sex & $\mathrm{Y}$ & $(0.471)$ \\
Age & $\mathrm{Y}$ & $\mathrm{Y}$ \\
Constant & $0.290^{* *}$ & $\mathrm{Y}$ \\
& $(0.0405)$ & $0.286^{* *}$ \\
Observations & 7,171 & $(0.0393)$ \\
\hline Note. Standard errors in parentheses; ${ }^{*} p<.05 ;{ }^{* *} p<.01 ;{ }^{* * *} p<.001$. &
\end{tabular}

Note. Standard errors in parentheses; ${ }^{*} p<.05 ;{ }^{* *} p<.01 ;{ }^{* * *} p<.001$.

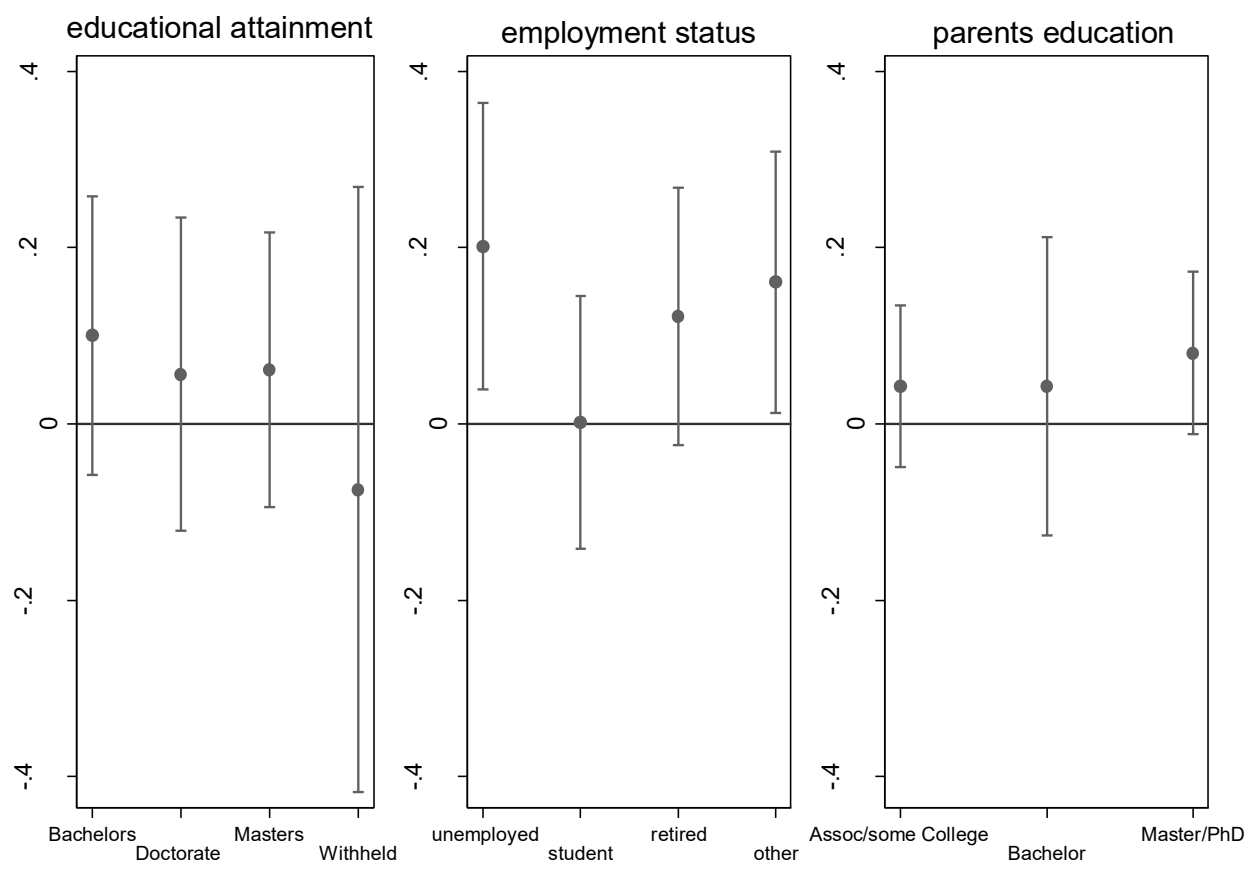

Figure 4. America's poverty \& inequality, average marginal effects for outcome = engagement

Table 6. America's poverty \& inequality. Estimates from logistic regression including interactions (odds ratio)

\begin{tabular}{lccc}
\hline & $\begin{array}{c}(1) \\
\text { Outcome= } \\
\text { engagement }\end{array}$ & $\begin{array}{c}(2) \\
\text { Outcome= } \\
\text { engagement }\end{array}$ & $\begin{array}{c}(3) \\
\text { Outcome= } \\
\text { engagement }\end{array}$ \\
\hline $\begin{array}{l}\text { Employment status (ref=FT employed) } \\
\text { Unemployed }\end{array}$ & $2.255^{*}$ & 2.017 & $2.262^{*}$ \\
Student & $(0.860)$ & $(0.850)$ & $(0.866)$ \\
& 0.910 & 0.831 & 0.916 \\
Retired & $(0.291)$ & $(0.302)$ & $(0.291)$ \\
& 1.664 & 1.847 & 1.617 \\
Other & $(0.533)$ & $(0.650)$ & $(0.515)$ \\
Education (ref = associate degree or less) & $1.975^{*}$ & 1.474 & 1.804 \\
Bachelor's & $(0.668)$ & $(0.562)$ & $(0.601)$ \\
Doctorate & 1.253 & & \\
& $(0.501)$ & 1.591 & 1.560 \\
Master's/prof. Degree & 1.127 & $1.581)$ & $(0.561)$ \\
Withheld & $(0.505)$ & $(0.543)$ & 1.283 \\
Parental education (ref $=$ high school or less) & 1.161 & 1.409 & 1.359 \\
Associate/some college & $(0.457)$ & $(0.511)$ & $(0.484)$ \\
& 1.106 & 0.796 & 0.827 \\
& $(0.970)$ & $(0.697)$ & $(0.701)$ \\
\end{tabular}




\begin{tabular}{|c|c|c|c|}
\hline \multirow{3}{*}{ Bachelor's } & $(0.249)$ & $(0.251)$ & $(0.269)$ \\
\hline & 1.138 & 1.202 & 1.167 \\
\hline & $(0.434)$ & $(0.457)$ & $(0.495)$ \\
\hline \multirow[t]{2}{*}{ Master's/phd } & 1.382 & 1.395 & 1.247 \\
\hline & $(0.288)$ & $(0.292)$ & $(0.289)$ \\
\hline Wrote at least one forum post (after the $2^{\text {nd }}$ video) & $\begin{array}{c}1.385 \\
(1.069)\end{array}$ & $\begin{array}{c}2.772 * * \\
(0.656)\end{array}$ & $\begin{array}{l}2.380^{*} \\
(0.824)\end{array}$ \\
\hline \multicolumn{4}{|l|}{ Interaction education \& post } \\
\hline Bachelor's \& post & $\begin{array}{c}2.655 \\
(2.258)\end{array}$ & & \\
\hline Doctorate \& post & $\begin{array}{c}2.106 \\
(1.923)\end{array}$ & & \\
\hline Master's/prof.degree \& post & $\begin{array}{c}2.160 \\
(1.779)\end{array}$ & & \\
\hline \multicolumn{4}{|l|}{ Interaction employment $\&$ post } \\
\hline Unemployed \& post & & $\begin{array}{c}2.247 \\
(2.620)\end{array}$ & \\
\hline Student \& post & & $\begin{array}{c}1.353 \\
(0.977)\end{array}$ & \\
\hline Retired \& post & & $\begin{array}{c}0.644 \\
(0.381)\end{array}$ & \\
\hline Other \& post & & $\begin{array}{c}2.626 \\
(2.339)\end{array}$ & \\
\hline \multicolumn{4}{|l|}{ Interaction parental edu \& post } \\
\hline Associate/Some College \& post & & & $\begin{array}{c}1.142 \\
(0.562)\end{array}$ \\
\hline Bachelor's \& post & & & $\begin{array}{c}1.045 \\
(0.950)\end{array}$ \\
\hline Master's/phd \& post & & & $\begin{array}{c}1.681 \\
(0.833)\end{array}$ \\
\hline Sex & Y & Y & $\mathrm{Y}$ \\
\hline Age & Y & Y & Y \\
\hline Constant & $\begin{array}{c}0.554 \\
(0.244)\end{array}$ & $\begin{array}{c}0.477 \\
(0.201)\end{array}$ & $\begin{array}{c}0.500 \\
(0.211)\end{array}$ \\
\hline Observations & 710 & 711 & 711 \\
\hline
\end{tabular}

Note. Standard errors in parentheses; ${ }^{*} p<.05 ;{ }^{* *} p<.01 ;{ }^{* * *} p<.001$.

With respect to the moderating effect of participation in forum discussions (Table 6), the estimates do not report any significant interaction of participation in forum discussions and the main predictors of SES. As for the case of attainment of a certificate of completion, participating in the forum discussion does not moderate the main effect of the SES predictors considered.

Consequently, findings for the API course suggest that availability of time is a crucial resource in determining the chances of staying engaged (unemployed and inactive learners are those who presumably have greater availability of time), while participation to forum discussions does not impact differently on different groups of learners.

\section{Conclusions}

This study analyzed the relationship between the socio-economic background of learners, their engagement, completion and participation in MOOCs. The main aim was to test whether some of the forms of social inequalities observed in the domain of traditional formal education apply also to the digital environment of MOOCs, but also whether MOOCs may, to some extent, help reach certain underprivileged groups in unforeseen ways.

Overall, findings support the main hypotheses of this research. Estimates from logistic regressions on the chances of attaining a certificate of completion and remaining engaged for at least $60 \%$ of the course material support the hypothesis of a negative association between low SES and outcome variables, though with some peculiarities. 
In line with the hypothesis formulated, results for the SL course show that learners with a university education have a higher chance of completing as well as staying engaged in course materials. Contrary to that hypothesized, unemployed learners also show a higher chance of attaining a certificate of completion (compared to employed peers) and, to a lesser extent, of remaining engaged in the course activities.

Findings for the API course show the relative advantage of a particular group of learners: completely inactive people who are not employed, not seeking job and not in formal education. This group, mainly consisting of adult female learners, shows a higher chance of completing and staying engaged in the course. We speculate that this may represent a relatively advantaged group, made up of individuals who can afford to remain outside the labor market, without working and without seeking employment, supporting the idea that wealthier individuals tend to have a higher chance of achieving positive outcomes in MOOCs. When considering the alternative outcome variable, "engagement," unemployed people also show a higher chance compared to employed peers. This seems to suggest that greater availability of time can be a crucial factor for staying engaged (both inactive and unemployed learners are likely to have more time than their peers) but, for unemployed people, not enough to attain a certificate.

Moreover, findings seem to indicate that learners may attribute different uses to the courses considered. Following the terminology of Max Weber's theory of social action, we distinguished between "goal-rational" and "value-rational" types of social action in MOOCs. The higher chances of completion shown by people excluded from the labor market in SL could indicate that learners may rationally decide to complete the course in order to improve their employment opportunities, based on the expectation that prospective employers may appreciate this as a signal of their competences and willingness to reskill (or upskill). On the contrary, API learners may act on the basis of value-rational considerations, based on shared concerns relating to social problems.

Finally, our analysis shows an ambiguous moderating role of the participation in online discussion forums. Participation in an online forum does not change the original advantage of certain groups; rather, when slightly significant, it tends to reinforce this advantage. This finding does not support the "technicist" hypothesis attributing a positive moderating effect of the online discussion forum. On the contrary, findings provide support for the alternative explanation associated with the Bourdieu concept of cultural capital. In this framework, higher cultural and cognitive skills of people with higher educational levels represent a further advantage: make them more confident and more prone to interact in the online discussion forum, ultimately further advantaging them in the learning process, delineating a typical "Mathew effect" (see Merton, 1968).

Our findings have implications on course design. If participation does not moderate or if, when it does, it tends to reinforce the advantage of well-educated people or those who can afford to remain outside the labor market, interventions in the course design targeted at overcoming barriers for all learners may contribute to reshaping the trend. Participation in forums may be incentivized and targeted toward certain goals by: (i) making it a substantial part of the total grading; (ii) making it more attractive and user-friendly; (iii) providing regular message alerts; (iv) regulating the maximum length or number of posts per learner (in order to avoid "superposters") or even (v) making it mandatory for attaining the certificate.

This study also presents some limitations that future empirical research needs to explore: the limited number of courses analyzed and the lack of proper measures for assessing the socio-economic background of learners. Nevertheless, this study significantly contributes to addressing a pragmatic question: "While MOOCs may not be ideal, can they at least represent a viable option for some learners and in some circumstances?" (Literat, 2015, p. 1173). The higher likelihood that unemployed individuals will complete the course with a certificate, and the arguable differential value of the two courses suggest that MOOCs may serve different needs, emerging from different types of user, attributing various functions to a flexible educational tool like the MOOC.

\section{Acknowledgement}

The authors thank the Center for Advanced Research through Online Learning (CAROL) at Stanford University for the provision of data and Mitchell Stevens for his support and collaboration during the project.

This project has received funding from the H2020-MSCA-IF-2016 program under grant agreement no. 750242. The work reflects only the author's view and the Commission is not responsible for any use that may be made of the information it contains. 


\section{References}

Almeda, M. V., Zuech, J., Baker, R. S., Utz, C., Higgins, G., \& Reynolds, R. (2018). Comparing the factors that predict completion and grades among for-credit and open/MOOC students in online learning. Online Learning, 22(1), 1-18. doi:10.24059/olj.v22i1.1060

Beard, L. A., Harper, C., \& Riley, G. (2004). Online versus on-campus instruction: Student attitudes \& perceptions. TechTrends, 48(6), 29-31. doi:10.1007/BF02763579

Bernardi, F., \& Ballarino, G. (2014). Participation, equality of opportunity and returns to tertiary education in contemporary Europe. European Societies, 16(3), 422-442. doi:10.1080/14616696.2012.750729

Bernardi, F., Hertel, F. R., \& Yastrebov, G. (2018). A U-turn in inequality in college attainment by parental education in the US? Research in Social Stratification and Mobility 58, 33-43. doi:10.1016/j.rssm.2018.09.003

Blau, P. M., \& Duncan, O. D. (1967). The American occupational structure. New York, NY: John Wiley \& Sons.

Breen, R. (2010). Educational expansion and social mobility in the 20th Century. Social Forces, 89(2), 365-388. doi:10.1353/sof.2010.0076

Breen, R., \& Jonsson, J. O. (2005). Inequality of opportunity in comparative perspective: Recent research on educational attainment and social mobility. Annual Review of Sociology, 31(1), 223-243. doi:10.1146/annurev.soc.31.041304.122232

Castaño-Muñoz, J., Kreijns, K., Kalz, M., \& Punie, Y. (2017). Does digital competence and occupational setting influence MOOC participation? Evidence from a cross-course survey. Journal of Computing in Higher Education, 29(1), 28-46. doi:10.1007/s12528-016-9123-z

Chang, J. C. (2005). Faculty-student interaction at the community college: A Focus on students of color. Research in Higher Education, 46(7), 769-802.

Emanuel, E. J. (2013). Online education: MOOCs taken by educated few. Nature, 503(7476), 342-342. doi:10.1038/503342a

Evans, B. J., \& Baker, R. B. (2016a). MOOCs and persistence: Definitions and predictors. In S. J. Blackmon \& C. H. Major (Eds.), MOOCs and Higher Education: Implications for Institutional Research (pp. 69-86). San Francisco, CA: Jossey-Bass.

Evans, B. J., Baker, R. B., \& Dee, T. S. (2016b). Persistence patterns in Massive Open Online Courses (MOOCs). The Journal of Higher Education, 87(2), 206-242. doi:10.1080/00221546.2016.11777400

Gallie, D., \& Paugam, S. (Eds.) (1999). Welfare regimes and the experience of unemployment in Europe. Oxford, UK: OUP Oxford.

Ganzeboom, H. B. G., De Graaf, P. M., \& Treiman, D. J. (1992). A standard international socio-economic index of occupational status. Social Science Research, 21(1), 1-56. https://doi.org/10.1016/0049-089X(92)90017-B

Gerber, T. P., \& Cheung, S. Y. (2008). Horizontal stratification in postsecondary education: Forms, explanations, and implications. Annual Review of Sociology, 34(1), 299-318. doi:10.1146/annurev.soc.34.040507.134604

Glass, C. R., Shiokawa-Baklan, M. S., \& Saltarelli, A. J. (2016). Who takes MOOCs? New Directions for Institutional Research, 2015(167), 41-55. doi:10.1002/ir.20153

Gunn, C., McSporran, M., Macleod, H., \& French, S. (2003). Dominant or different? Gender issues in computer supported learning. Journal of Asynchronous Learning Networks, 7(1). Retrieved from https://www.research.ed.ac.uk/portal/en/publications/dominant-or-different-gender-issues-in-computer-supportedlearning(2afd96a8-45ec-4a9f-8b83-4df79245ec84).html

Ho, A., Chuang, I., Reich, J., Coleman, C., Whitehill, J., Northcutt, C., Williams, J., Hansen, J., Lopez, G., \& Petersen, R. (2015). HarvardX and MITx: Two years of open online courses Fall 2012-Summer 2014. Retrieved from https://papers.ssrn.com/abstract $=2586847$

Hout, M. (2012). Social and economic returns to college education in the United States. Annual Review of Sociology, 38(1), 379-400. doi:10.1146/annurev.soc.012809.102503

Kizilcec, R. F., \& Halawa, S. (2015). Attrition and achievement gaps in online learning. In Proceedings of the Second ACM Conference on Learning @ Scale (pp. 57-66). New York, NY: Association for Computing Machinery. doi: $10.1145 / 2724660.2724680$

Kizilcec, R. F., Piech, C., \& Schneider, E. (2013). Deconstructing disengagement: Analyzing learner subpopulations in massive open online courses. In Proceedings of the Third International Conference on Learning Analytics and Knowledge (LAK'13) (pp. 170-179). New York, NY: Association for Computing Machinery. doi:10.1145/2460296.2460330

Kizilcec, R. F., \& Saltarelli, A. J. (2019, June 24). Can a diversity statement increase diversity in MOOCs? In Proceedings of the Sixth (2019) ACM Conference on Learning@ Scale (pp. 1-8). New York, NY: Association for Computing Machinery. doi: $10.1145 / 3330430.3333633$ 
Kollock, P., \& Smith, M. (1996). Managing the virtual commons: Cooperation and conflict in computer communities. In S. Herring (Ed.), Computer-Mediated Communication: Linguistic, Social, and Cross-Cultural Perspectives (pp. 109-128). Amsterdam, NL: John Benjamins. Retrieved from https://www.researchgate.net/publication/215643656_Managing_the_Virtual_Commons_Cooperation_and_Conflict_in_Com puter_Communities

Leeper, T. J. (2018). Interpreting regression results using average marginal effects with R's margins. Retrieved from https://cran.r-project.org/web/packages/margins/vignettes/TechnicalDetails.pdf

Literat, I. (2015). Implications of massive open online courses for higher education: Mitigating or reifying educational inequities? Higher Education Research \& Development, 34(6), 1164-1177. doi:10.1080/07294360.2015.1024624

Lucas, S. R. (2001). Effectively Maintained Inequality: Education Transitions, Track Mobility, and Social Background Effects. The American Journal of Sociology, 106(6), 1642-1690.

Mare, R. D. (1981). Change and stability in educational stratification. American Sociological Review, 46(1), $72-87$.

Merton, R. K. (1968). The Matthew effect in science. Science, 159(3810), 56-63.

OECD. (2018). Youth not in employment, education or training (NEET) [Data set]. OECD. doi:10.1787/72d1033a-en

Reich, J. (2014). MOOC completion and retention in the context of student intent. Educause Review. Retrieved from https://er.educause.edu/articles/2014/12/mooc-completion-and-retention-in-the-context-of-student-intent

Rocca, K. A. (2010). Student participation in the college classroom: An Extended multidisciplinary literature review. Communication Education, 59(2), 185-213. doi:10.1080/03634520903505936

Roksa, J., Grodsky, E., Arum, R., \& Gamoran, A. (2007). United States: Changes in higher education and social stratification. In Y. Shavit, R. Arum, \& A. Gamoran (Eds.), Stratification in Higher Education: A Comparative Study (pp. 167-191). Stanford, CA: Stanford University Press.

Rosenbaum, J. E., Deil-Amen, Regina, \& Person, A. E. (2009). After admission: From college access to college success. New York, NY: Russell Sage Foundation.

Ruthotto, I., Kreth, Q., Stevens, J., Trively, C., \& Melkers, J. (2020). Lurking and participation in the virtual classroom: The Effects of gender, race, and age among graduate students in computer science. Computers \& Education, 151, 103854. doi:10.1016/j.compedu.2020.103854

Sallaz, J. J., \& Zavisca, J. (2007). Bourdieu in American Sociology, 1980-2004. Annual Review of Sociology, 33(1), $21-41$. doi:10.1146/annurev.soc.33.040406.131627

Schizzerotto, A., \& Barone, C. (2012). Sociologia dell'istruzione [Sociology of education]. Bologna, IT: il Mulino

Shah, D. (2019). Year of MOOC-based degrees: A Review of MOOC stats and trends in 2018 - Class Central. Class Central's MOOC Report. Retrieved from https://www.class-central.com/report/moocs-stats-and-trends-2018/

Sharrock, G. (2015). Making sense of the MOOCs debate. Journal of Higher Education Policy and Management, 37(5), 597609. doi:10.1080/1360080X.2015.1079399

Shavit, Y., Arum, R., Gamoran, A., \& Menachem, G. (Eds.) (2007). Stratification in higher education: A Comparative study. Stanford, CA: Stanford University Press.

Shavit, Y., \& Blossfeld, H.-P. (Eds.) (1993). Persistent inequality: Changing educational attainment in thirteen countries. Boulder, CO: Westview Press.

Triventi, M. (2013). The Role of higher education stratification in the reproduction of social inequality in the labor market. Research in Social Stratification and Mobility, 32, 45-63. doi:10.1016/j.rssm.2013.01.003

Triventi, M., Vergolini, L., \& Zanini, N. (2017). Do individuals with high social background graduate from more rewarding fields of study? Changing patterns before and after the "Bologna process." Research in Social Stratification and Mobility, 51, 28-40. doi:10.1016/j.rssm.2017.07.001

van de Oudeweetering, K., \& Agirdag, O. (2018a). MOOCS as accelerators of social mobility? A Systematic review. Educational Technology \& Society, 21(1), 1-11.

van de Oudeweetering, K., \& Agirdag, O. (2018b). Demographic data of MOOC learners: Can alternative survey deliveries improve current understandings? Computers \& Education, 122, 169-178. doi:10.1016/j.compedu.2018.03.017

Wang, Y., \& Baker, R. (2018). Grit and intention: Why do learners complete MOOCs? The International Review of Research in Open and Distributed Learning, 19(3). doi:10.19173/irrodl.v19i3.3393

Weber, M. [1922] 1978. Economy and Society. Berkeley, CA: University of California Press. 
Zhang, D. J., Allon, G., \& Van Mieghem, J. A. (2017). Does social interaction improve learning outcomes? Evidence from field experiments on massive open online courses. Manufacturing \& Service Operations Management, 19(3), $347-367$. doi: $10.1287 / \mathrm{msom} .2016 .0615$

\section{Appendix A}

Statistical learning: Estimates from logistic regression (odds ratio) for both outcome variables

\begin{tabular}{lcc}
\hline & Model 1 & Model 2 \\
\hline & Outcome certificate & Outcome = engagement \\
employment status (ref= FT employed) & & 1.074 \\
PT employed & $(0.109)$ & $(0.115)$ \\
Student & 1.107 & 1.141 \\
& $(0.0844)$ & $(0.0874)$ \\
Unemployed & $1.323^{* *}$ & $(0.1196$ \\
& $(0.126)$ & 1.075 \\
Retired & 1.160 & $(0.294)$ \\
& $(0.335)$ & 0.986 \\
Education (ref= less than BA) & & $(0.117)$ \\
Bachelor's & 0.945 & $1.734^{* *}$ \\
& $(0.109)$ & $(0.238)$ \\
Doctorate & $1.755^{* *}$ & $\left(.281^{*}\right.$ \\
Master's/professional degree & $(0.235)$ & $(0.157)$ \\
Withheld & 1.257 & 1.333 \\
Sex & $(0.150)$ & $(0.347)$ \\
Age & 0.942 & $(0.0457)$ \\
Constant & $(0.247)$ & 7,239 \\
\hline
\end{tabular}

Note. Standard errors in parentheses; ${ }^{*} p<.05 ;{ }^{* *} p<.01$. 


\section{Appendix B}

America's Poverty \& Inequality. Estimates from logistic regression (odds ratio) for both outcome variables

\begin{tabular}{|c|c|c|}
\hline & $\begin{array}{c}\text { Model } 1 \\
\text { Outcome = certificate }\end{array}$ & $\begin{array}{c}\text { Model } 2 \\
\text { Outcome = Engagement }\end{array}$ \\
\hline \multicolumn{3}{|l|}{ Employment status } \\
\hline Unemployed & $\begin{array}{c}1.331 \\
(0.446)\end{array}$ & $\begin{array}{l}2.349^{*} \\
(0.872)\end{array}$ \\
\hline Student & $\begin{array}{c}0.934 \\
(0.285)\end{array}$ & $\begin{array}{c}1.008 \\
(0.311)\end{array}$ \\
\hline Retired & $\begin{array}{l}1.213 \\
(0.357)\end{array}$ & $\begin{array}{l}1.664 \\
(0.518)\end{array}$ \\
\hline Other & $\begin{array}{l}2.562^{* *} \\
(0.793)\end{array}$ & $\begin{array}{l}1.965^{*} \\
(0.640)\end{array}$ \\
\hline \multicolumn{3}{|l|}{ Education } \\
\hline Bachelor's & $\begin{array}{c}1.573 \\
(0.540)\end{array}$ & $\begin{array}{c}1.540 \\
(0.546)\end{array}$ \\
\hline Doctorate & $\begin{array}{c}1.387 \\
(0.536)\end{array}$ & $\begin{array}{c}1.277 \\
(0.506)\end{array}$ \\
\hline Master's/professional degree & $\begin{array}{c}1.173 \\
(0.401)\end{array}$ & $\begin{array}{c}1.304 \\
(0.457)\end{array}$ \\
\hline Withheld & $\begin{array}{c}0.939 \\
(0.735)\end{array}$ & $\begin{array}{c}0.710 \\
(0.590)\end{array}$ \\
\hline \multicolumn{3}{|l|}{ Parents' education } \\
\hline Associate/some college & $\begin{array}{c}1.097 \\
(0.216)\end{array}$ & $\begin{array}{c}1.202 \\
(0.242)\end{array}$ \\
\hline Bachelor's & $\begin{array}{l}1.096 \\
(0.389)\end{array}$ & $\begin{array}{l}1.203 \\
(0.446)\end{array}$ \\
\hline Master's/phd & $\begin{array}{l}1.395 \\
(0.274)\end{array}$ & $\begin{array}{c}1.412 \\
(0.287)\end{array}$ \\
\hline Sex & $\mathrm{Y}$ & $\mathrm{Y}$ \\
\hline Age & Y & Y \\
\hline Constant & $\begin{array}{c}0.370^{*} \\
(0.150) \\
0.0369\end{array}$ & $\begin{array}{c}0.536 \\
(0.220) \\
0.0449\end{array}$ \\
\hline Observations & 824 & 711 \\
\hline
\end{tabular}

Note. Standard errors in parentheses; ${ }^{*} p<.05 ;{ }^{* *} p<.01$. 